\title{
Prediction of Renal Cortical Involvement Using Serum and Urinary Inflammatory Markers in Children with Febrile Urinary Tract Infection
}

\author{
Mitra Naseri, ${ }^{1,}{ }^{*}$ Malihe Banihasan, ${ }^{1}$ and Seyed Ali Alamdaran ${ }^{2}$ \\ ${ }^{1}$ Department of Nephrology, Dr. Sheikh Children Hospital, Mashhad University of Medical Sciences, Mashhad, Iran \\ ${ }^{2}$ Department of Radiology, Dr. Sheikh Children Hospital, Mashhad University of Medical sciences, Mashhad, Iran \\ "Corresponding author: Mitra Naseri, Department of Nephrology, Mashhad University of Medical sciences, Naderi Avenue, Taabodi Street, Dr. Sheikh Children Hospital, \\ Mashhad, Iran. Tel: +98-5137269021-25; +98-9151141639, Fax:+98-5137273943, E-mail: Naserim@mums.ac.ir
}

Received 2016 August 20; Revised 2016 December 05; Accepted 2017 January 04.

\begin{abstract}
Background: Erythrocyte sedimentation rate(ESR), serum C-reactive protein (CRP), urinary $\beta 2$ microglobulin, antibody-coated bacteria in the urine sediment, and urinary lactic dehydrogenase (LDH) are more traditional tests used to diagnose true pyelonephritis. Acute-phase dimercaptosuccinic acid (DMSA) scan is a sensitive method for diagnosis of true pyelonephritis.

Objectives: Defining predictive values of traditional inflammatory serologic parameters, urine analysis indexes, kidney ultrasonography and fever in children with febrile urinary tract infection for predicting renal cortical involvement.

Patients and Methods: In a prospective study, 20 children admitted due to febrile urinary tract infection were assessed for renal cortical involvement by Technetium-99 m-labeled dimercapto succinic acid (TC99-DMSA) scan. Body temperature $\geq 39 \mathrm{C}$, white blood cell count $\geq 15000$ cell $/ \mu \mathrm{L}$, positive C-reactive protein, erythrocyte sedimentation rate (first hour) $\geq 30 \mathrm{~mm} / \mathrm{h}$, presence of proteinuria, severe pyuria or bacteriuria on urine analysis, urine specific gravity $\leq 1010$, and renal ultrasonography were used for predicting renal cortical involvement. Sensitivity, specificity, positive and negative predictive values of these variables were measured by specific formula.

Results: The highest measured sensitivity was $100 \%$ (erythrocyte sedimentation rate $\geq 30 \mathrm{~mm} / \mathrm{h}$ ). Urine specific gravity $<1010$ and bacteriuria had the highest (75\%) and lowest (20\%) specificities respectively. The highest and lowest positive predictive values were 85.7\% ( urine specific gravity < 1010) and 57\% (proteinuria), whereas the highest and lowest negative predictive values were related to erythrocyte sedimentation rate $>30 \mathrm{~mm} / \mathrm{h}(100 \%)$ and proteinuria (11\%) respectively. Normal sonography had a low sensitivity for predicting absence of renal involvement (23\%).

Conclusions: Erythrocyte sedimentation rate $\geq 30 \mathrm{~mm} / \mathrm{h}$ is a sensitive marker with high negative predictive value for predicting renal involvement in febrile urinary tract infection.
\end{abstract}

Keywords: Febrile UTI, Tc99- DMSA Scan, Renal Parenchymal Involvement

\section{Introduction}

Urinary tract infection (UTI) is common in children. It is confirmed by urine culture $(\mathrm{U} / \mathrm{C})$ as the gold standard test. Not infrequently $\mathrm{U} / \mathrm{C}$ is negative in acute pyelonephritis (APN) such as in patients who take antibiotics before urine sampling. The development of easy accessible alternative methods for diagnosis of acute pyelonephritis that is associated with parenchymal involvement and commonly progressed to renal cortical injuries especially in infants (1), is an attractive topic in the field of pediatric urology researches.

In febrile patients, a positive $\mathrm{U} / \mathrm{C}$ is not as sensitive as Technetium 99 Dimercapto Succinic Acid (TC 99- DMSA) scanning for diagnosis of APN (2). Acute-phase DMSA scan shows renal changes in $16.3 \%$ of infants experiencing their first febrile UTI (3). Clinical studies have demonstrated that dimercaptosuccinic acid (DMSA) scan is significantly more sensitive than either intravenous pyelography (IVP) or ultrasonography (US) in the diagnosis of acute pyelonephritis (4-8). Serologic and urinary inflammatory markers such as erythrocyte sedimentation rate (ESR), C-reactive protein (CRP), urinary $\beta 2$ microglobulin, antibody-coated bacteria in the urine sediment, and urinary lactic dehydrogenase (LDH) are used for diagnosis of true APN (4). Early diagnosis and aggressive treatment of APN can prevent or diminish renal scarring following febrile UTI in the childhood period (9-11). Serologic markers such as ESR, CRP, white blood cell (WBC) count are traditional markers that are commonly used for the diagnosis of pyelonephritis (1214) but cannot reliably differentiate APN from cystitis. The first one is characterized by renal parenchymal involvement and the latter without it (13). Another study showed that ESR and differential leukocyte count are valuable tests 
for defining the localization of UTI level (14). Also urine analysis and renal US are easy available tests. Few data are available about the role of urinary indexes as markers of pyelonephritis (15-17) and conventional kidney US has very low sensitivity (11\% - 40\%) for predicting renal parenchymal lesions in $\operatorname{APN}(8,18)$.

\section{Study Objective and Hypothesis}

We aimed to determine whether traditional serologic markers of inflammation, urine dipstick test and sediment findings, systemic response to infection (severity of fever) and renal US findings can predict renal parenchymal involvement in cases with clinical diagnosis of acute pyelonephritis and how much is common true pyelonephritis (renal parenchymal involvement ) in these patients? Based on our previous findings (14) we supposed that high ESR especially ESR $\geq 30 \mathrm{~mm} / \mathrm{h}$ may be a good indicator for renal involvement .

\section{Patients and Methods}

3.1. Study Design

The study was designed as a prospective study.

\subsection{Participants}

Cases admitted in hospital with febrile UTI (first or recurrent episodes of infections) were evaluated and those who did not undergo imaging studies for detection of urological anomalies [mainly voiding cystouretrogram (VCUG) and TC99-DMSA scan] were enrolled into the study.

\subsection{Test Methods}

The study was performed in an eleven- month period, in pediatric nephrology and emergency departments of an academic tertiary children hospital. Participants formed a consecutive series. Immediately after admission, urine analysis and culture, blood culture, complete blood cell (CBC) and differential cell counts, serum CRP and ESR were obtained, and antibiotic treatment was started. In infants and non-toilet trained cases, the urine samples were obtained by urine bags and in toilet trained patients by midstream method. Febrile UTI was diagnosed by presence of fever (body temperature $\geq 38.5^{\circ} \mathrm{C}$ ) in combination with pyuria and positive urine culture (growth of one microorganism with colony forming unit $\geq 50,000$ ). Kidneybladder US was performed in the first or second days of admission and patients underwent DMSA scan in days 2 - 4 of admission to determine cases with true pyelonephritis. Gamma equipped with a high-resolution collimator was used for renal scan imaging after intravenous injection of radiotracer as standard schedule (19).

Standards for reporting diagnostic accuracy studies (STARD) 2015 essential items were used for an informative study report (20). Index tests in our study consisted of ESR, CRP, leukocyte count, urine specific gravity (SG), proteinuria, bacteriuria and the severity of pyuria in urine analysis (U/A), body temperature and renal ultrasonography and reference standard. The best available method for establishing presence or absence of the target condition (renal parenchymal involvement) in our study was TC 99 DMSA scan. No alternative as reference standard was available. Test positivity cut-offs or result categories of the index test were chosen based on literature review (12-17, 21-23). Clinical information and reference standard results were not available to the performers/readers of the index test, and also clinical information and index test results were not available to the assessors of the reference standard.

\subsection{Analysis}

Only one kidney US was done for every patient. All kidney ultra-sonographies were done by two radiologists who were expert in pediatric kidney sonography. Because of some limitations, kidneys ultrasonographies were not repeated to compare results and to assess inter rater reliability. Sample size was determined by duration of the study and as the study was the thesis of a medical student, the duration of the study was limited. A significant percent of cases who were admitted with febrile UTI in the length of the study were excluded because they had recurrence of infection and imaging studies were done in the past. In addition, a small group of patients who had the inclusion criteria did not accept to be enrolled the study.

Student's test was used for data analysis and P values $\leq 0.05$ were considered as statistically different. Based on the results of Tc-99 DMSA scintigraphy, cases were categorized into two groups: patients with normal (no defect on renal scan) and those with abnormal (single or multiple defects on renal scan). Age, ESR1 (mm/h), total blood WBC count (cells $/ \mu \mathrm{L}$ ), differential count of polymorphonuclear (PMN) cells (\%), urine specific gravity (SG), and body temperature during admission (degree of Celsius; ${ }^{\circ} \mathrm{C}$ ) were compared between groups. In addition, positive and negative predictive values, sensitivity and specificity of some variables such as body temperature $\geq 39 \mathrm{C}$, WBC count $\geq$ 15,000 cell $/ \mu \mathrm{L}$, positive CRP, ESR $1 \geq 30 \mathrm{~mm} / \mathrm{h}$, presence of proteinuria, severe pyuria (reporting many $\mathrm{WBC}$ in $\mathrm{U} / \mathrm{A}$ ) or bacteriuria on urine analysis (U/A), and SG $\leq 1010$ were assessed for predicting renal cortical involvement. These assessments were carried out for normal renal US to predict the absence of renal defect/defects. Oral consents were obtained. Sensitivity was the proportion of those with renal 
uptake defect/defects on TC 99 DMSA scan who had positive index tests and specificity was the proportion of those without renal uptake defect on TC 99 DMSA scan who had negative index tests. The study was funded by a research grant and approved by the local ethic committee. Medical records of cases were registered in a questioner.

\section{Results}

\subsection{Participants}

In the current study, different index tests were assessed. STARD flow (Figure 1) shows the results of the study for ESR $\geq 30 \mathrm{~mm} / \mathrm{h}$ as index test and TC 99-DMSA scan as reference standard. The enrolled cases included 19 girls (95\%) and one boy (5\%). Details of the enrolled cases are presented in Table 1 . Two cases were admitted with a body temperature higher than $38.5^{\circ} \mathrm{C}$. Their temperature suddenly decreased after starting antibiotics and antipyretic drugs (acetaminophen). Their highest body temperatures that were registered during hospitalization were 37.5 and $38^{\circ} \mathrm{C}$. Diagnosis of febrile UTI is made by association of clinical manifestations and positive U/C. Frequently, because of receiving antibiotics before urine sampling, pyuria is present, but U/C may be negative (sterile pyuria). In these cases, if there is a high clinical suspicion of pyelonephritis, renal scintigram can confirm the diagnosis. Renal parenchymal defects in TC99-DMSA scan in these cases confirm the diagnosis of pyelonephritis. In our series in 4 (20\%) cases urine cultures were negative and diagnosis of febrile UTI was confirmed by renal scintigram. TC99-DMSA scans showed abnormal findings in 15 (75\%), including single $(3 ; 15 \%)$ or multiple $(12 ; 60 \%)$ uptake defects. In patients with multiple defects, defects were limited to one kidney in $6(50 \%)$ and reminders had multiple defects in both kidneys. Figures 2 and 3 show renal scans in two patients. Renal scan in two (10\%) cases revealed decreased kidney size that indicated permanent renal damage.

The gold standard for diagnosis of UTI is the positive urine culture. In our series no alternative diagnosis was not found for those with positive $\mathrm{U} / \mathrm{C}$ associated with fever and no defect on DMSA scan. There was a time interval of 2 - 4 days between index tests and reference standard and during this period, patients received recommended intravenous antibiotics. Figures 2 - 4 present details of some interesting enrolled patients focusing on DMSA scan, serologic and urinary findings.

\subsection{Test Results}

Table 2 compares details of patients with renal involvement with those without. Positive and negative predictive
Table 1. Patient Characteristics

\begin{tabular}{lccc}
\hline Characteristics & $\begin{array}{c}\text { Minimum- } \\
\text { Maximum }\end{array}$ & Mean \pm SD & Median \\
\hline Age, mo & $6-118$ & $33.4 \pm 30.3$ & 28.5 \\
\hline $\begin{array}{l}\text { Temperature, }{ }^{\circ} \mathrm{C} \\
\text { WBC }^{1} \text { count, } \\
\text { cells } / \mu \text { L }\end{array}$ & $37.5-40$ & $38.9 \pm 0.6$ & 39 \\
\hline $\begin{array}{l}\text { Differential PMN } \\
\text { count, } \%\end{array}$ & $7600-28600$ & $16323 \pm 5326$ & 16900 \\
\hline $\begin{array}{l}\text { Urine SG } \\
\text { 3 }\end{array}$ & $37-90$ & $61 \pm 14.7$ & 61 \\
\hline ESR & $1003-1020$ & $1008 \pm 4.6$ & \\
\hline
\end{tabular}

Abbreviations: ESR, erythrocyte sedimentation rate; PMN, polymorph nuclear; SG, specific gravity; WBC, white blood cells.

values, sensitivity and specificity of different variables (epidemiologic, laboratory, and US findings) were assessed in patients (Table 3). No adverse events were reported from performing the index test or the reference standard.

\section{Discussion}

Radiologic assessments are an important part of management of children with urinary tract infection. In recent years, the trend of using noninvasive imaging studies to define high-risk children is increasing. High-risk cases include those with true pyelonephritis (cases with evidence of renal parenchymal involvement in TC 99 DMSA scan) who are more prone to vesicoureteral reflux(VUR) and also develop renal parenchymal damage at follow-up. Imaging studies are the standard of care for young children with a first urinary tract infection to identify possible urinary tract abnormalities (VUR, obstruction, and ureteroceles), acute inflammation, and renal scarring. These factors predispose the child to recurrent infections or long-term sequels (24). In 2007, the European society of pediatric radiology recommended ultrasound examination for all pediatric UTI patients, and also early DMSA scanning if the ultrasound is normal and there is clinical suspicion of APN (25). It has been reported that $38 \%$ - 57\% of children with renal parenchymal defect/defects on renal scintigraphy will develop permanent renal scarring (26). These findings address the important role of DMSA scanning for screening high-risk cases.

A limitation for this type of approach is that DMSA scanning is sensitive in predicting high-risk cases only if it is done in the acute phase of infection. Whereas, in practice, radioisotope scans are not easily available in the majority of first or even secondary hospitals. An important question is that whether traditional serologic and urinary 


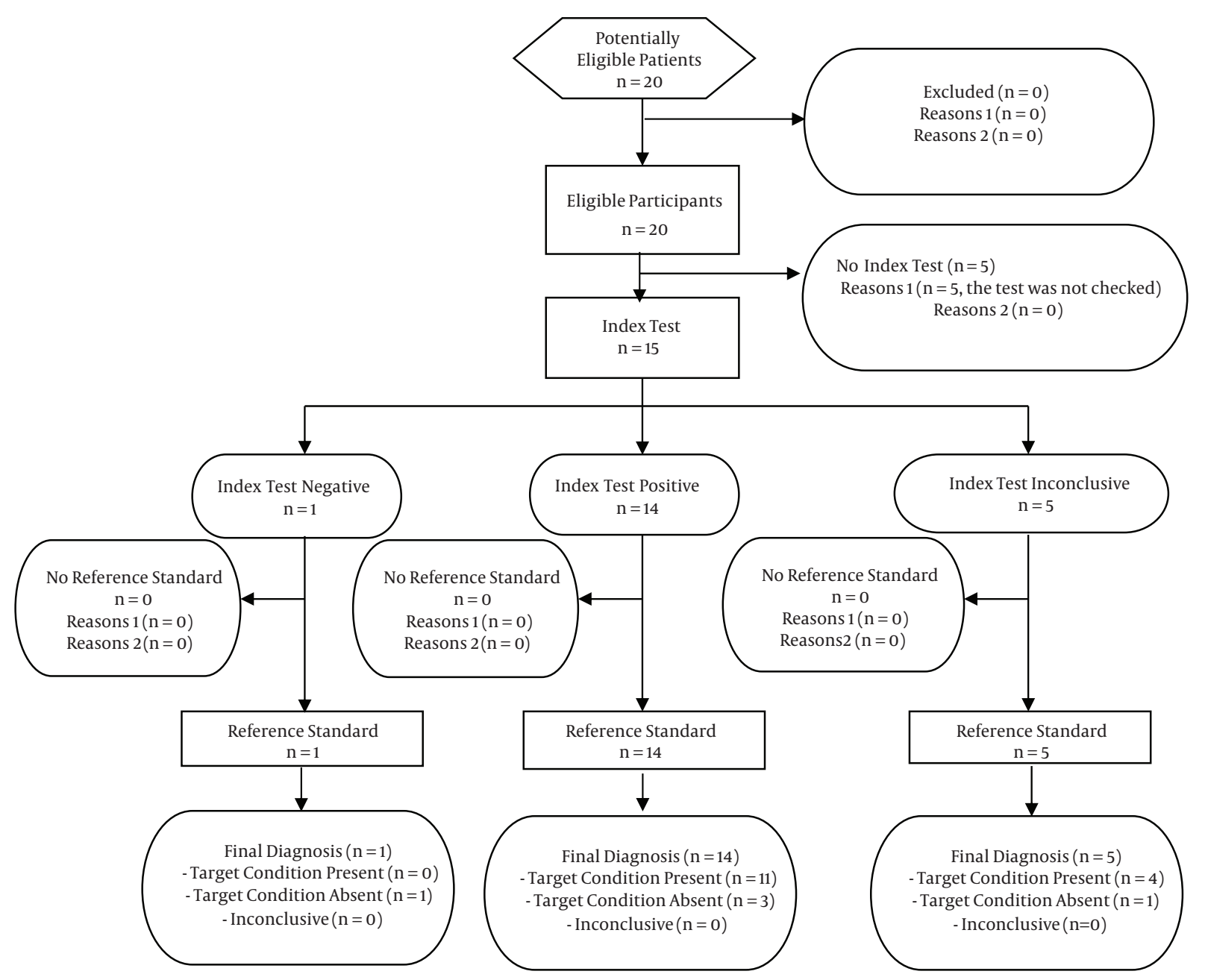

Figure 1. STARD Flow: prototypical standards for reporting diagnostic accuracy Studies (STARD) diagram to report flow participants through the study [with erythrocyte sedimentation rate (ESR) $\geq 30 \mathrm{~mm} / \mathrm{h}$ as index test]

Table 2. Comparing Cases With Renal Parenchyma Involvement in Renal Scan with Those Without ${ }^{\mathrm{a}}$

\begin{tabular}{|c|c|c|c|c|}
\hline Variable & Cases With Renal Defect /defects (15/75\%) & Cases Without Renal Defect (5/25\%) & PValue & CI 95\% \\
\hline Age, mo & $34.1 \pm 33.2$ & $31.2 \pm 22.1$ & 0.857 & -37.6 to 28.2 \\
\hline Body temperature, ${ }^{\circ} \mathrm{C}$ & $38.97 \pm 0.7$ & $38.8 \pm 0.24$ & 0.63 & -0.92 to 0.53 \\
\hline ESR, $\mathbf{m m} / \mathbf{h}$ & $65.4 \pm 21.4$ & $69.6 \pm 42$ & 0.807 & -37.2 to 47.4 \\
\hline WBC count, cells $/ \mu \mathrm{L}$ & $16315 \pm 5729$ & $16350 \pm 4470$ & 0.991 & -6244 to 8482 \\
\hline Differential cell count of PMN, \% & $61 \pm 14.6$ & $72 \pm 13$ & 0.2 & -6.4 to 24.9 \\
\hline Urine SG & $1007 \pm 3.6$ & $1011 \pm 6.3$ & 0.11 & -1.1 to 9.6 \\
\hline
\end{tabular}

Abbreviations: ESR, erythrocyte sedimentation rate; PMN, polymorph nuclear; SG, specific gravity; WBC, white blood cells.

${ }^{a}$ values expressed as mean $\pm S D$.

markers of inflammation are sensitive enough to predict those with renal parenchymal defects on DMSA scanning.
Although $\mathrm{U} / \mathrm{C}$ is the gold standard test for diagnosis of UTI, various clinical settings can result in negative re- 


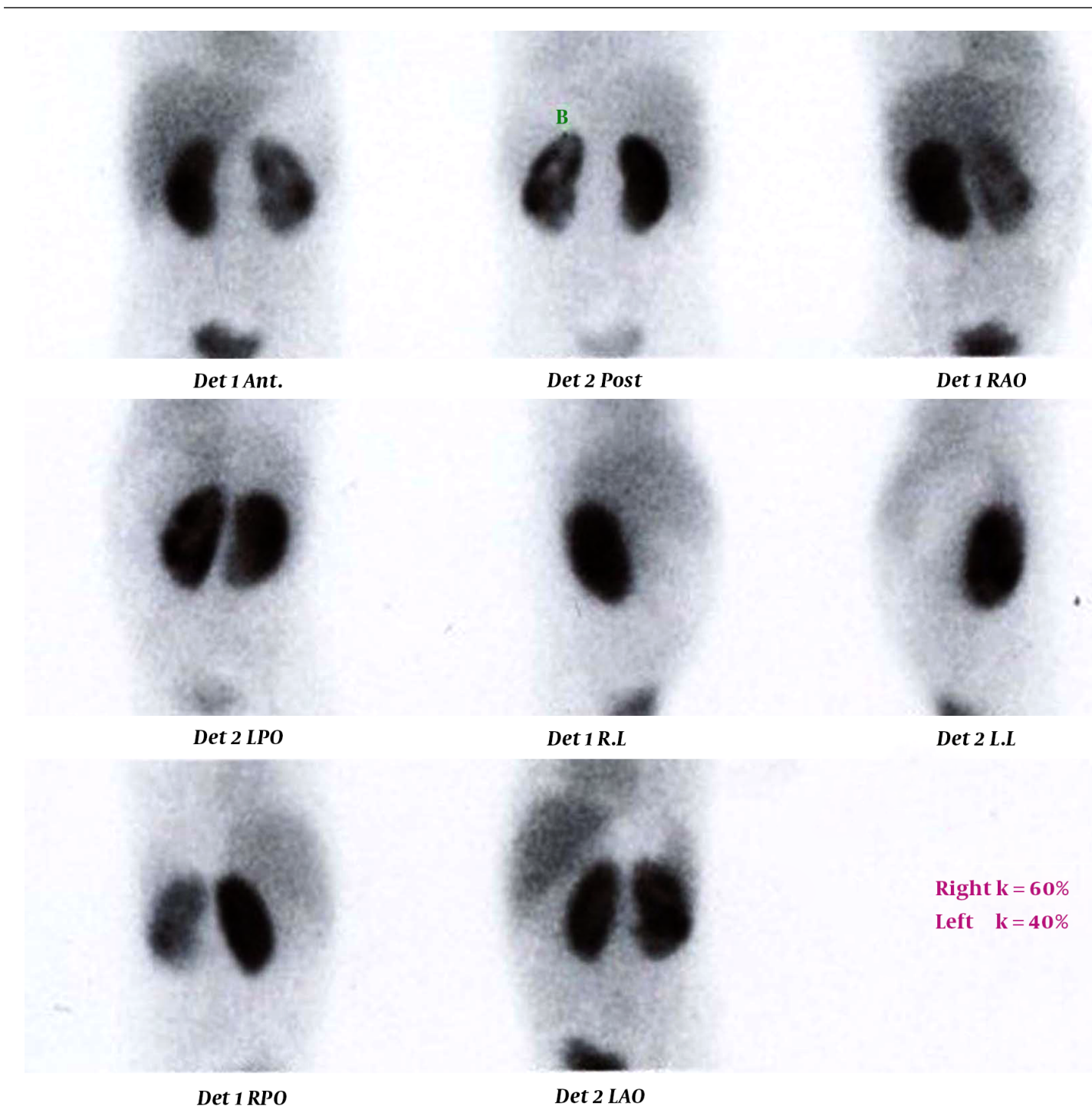

Figure 2. Technetium-99m dimercaptosuccinic acid (TC 99-DMSA) scan of a 4-year-old girl. Right kidney has normal size with no defect. Left kidney has normal size with global cortical loss and a cortical defect in the lower pole. The highest body temperature during admission was $39.4^{\circ} \mathrm{C}$. Urine examination showed specific gravity of 1010 , one plus protein, bacteriuria, positive nitrite test, and severe pyuria. Kidney-bladder sonography was normal. Blood tests revealed WBC count of 28,600 cells/ $\mu \mathrm{L}$ with polymorphonuclear (PMN) differential count of $90 \%$, erythrocyte sedimentation rate (ESR) $1=83 \mathrm{~mm} / \mathrm{h}$, C-reactive protein (CRP) levels were not checked.

sults (27). Serologic inflammatory markers can be helpful, but they are not pathognomonic $(28,29)$. Usefulness of TC 99-DMSA scan has been shown in culture negative febrile children for diagnosis of APN (30). Renal cortical defects have been reported in $59-63 \%$ of cases with febrile UTI $(8,31)$. We found TC 99- DMSA findings consistent with APN in 15 of 20 cases (75\%) with febrile UTI. Jung et al. (1) found that serum levels of CRP and urine protein /creatinine $(\mathrm{Pr} / \mathrm{Cr}$ ) ratio is higher in infants with APN than normal controls. Ninety six patients including 71 children with true APN (abnormal findings on renal scan) were evalu- ated for changes in urine and serum inflammatory markers (21). They found that fever, ESR, WBC count and differential cell count were not significantly different in cases with abnormal renal scan (true APN) compared with those without. Whereas, positive serum CRP levels were significantly more common in those with an abnormal scan. Sensitivity and specificity of CRP for predicting renal involvement were $60 \%$ and $70 \%$, respectively. In our series, age, body temperature $\left({ }^{\circ} \mathrm{C}\right), \operatorname{ESR} 1(\mathrm{~mm} / \mathrm{h}), \mathrm{WBC}$ count (cells $\left./ \mu \mathrm{L}\right)$, differential cell count of PMN (\%), and urine SG were not significantly different in cases with versus those without 


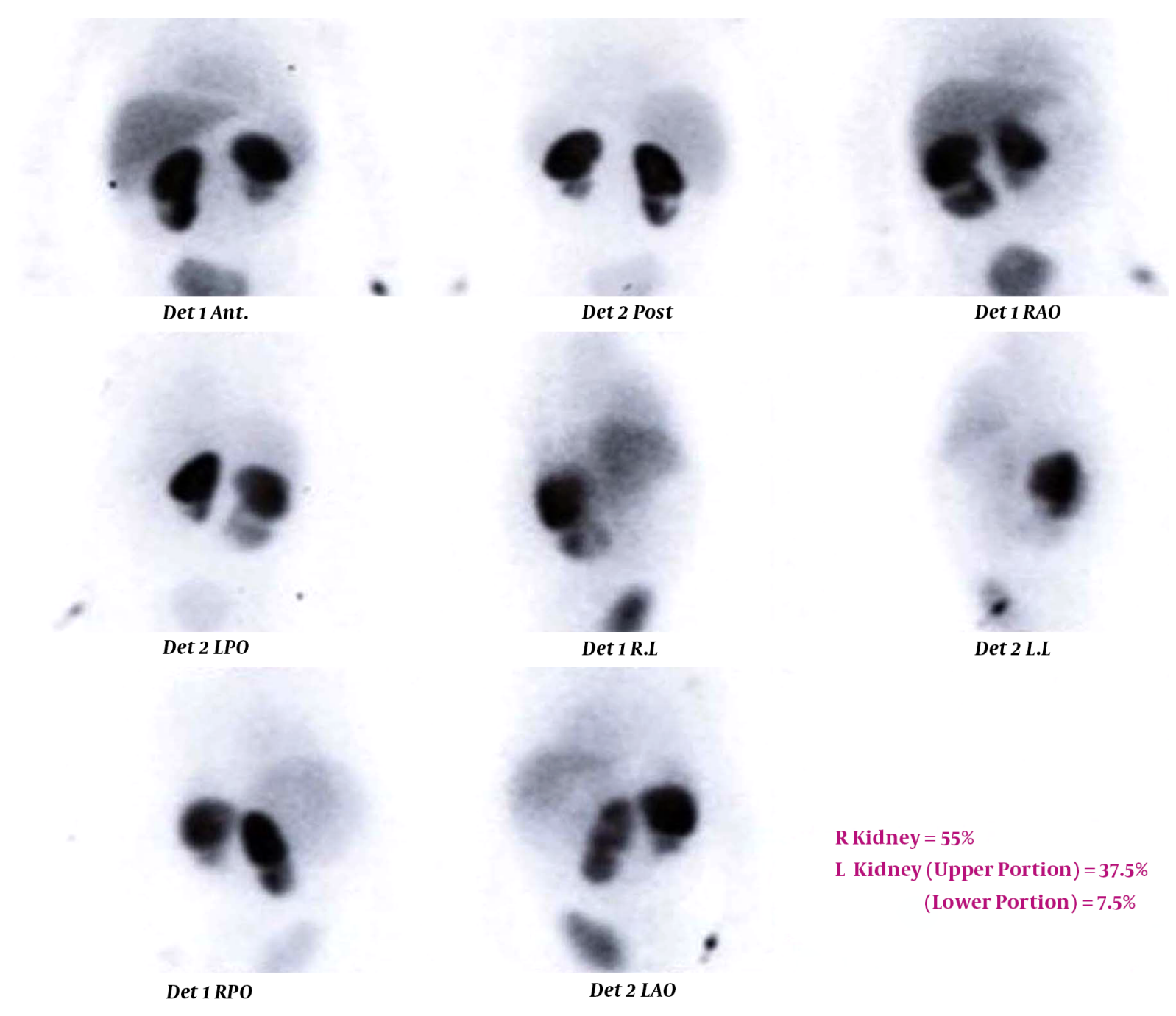

Figure 3. TC 99-DMSA scan of a 31-month-old girl with recurrent urinary tract infection (UTI). Right kidney has normal size with a cortical defect in the lower pole. Left kidney is small sized with cortical loss in the lower part which can be due to cortical scar or duplicated collecting system. Body temperature after admission and starting antibiotic immediately decreased, and the highest body temperature during admission was $37.5^{\circ} \mathrm{C}$. Urine examination showed specific gravity of 1005 , negative protein, bacteriuria, negative nitrite test, and severe pyuria. Kidney-bladder sonography showed duplicated left collecting system, small sized left kidney with multiple scars. Blood tests revealed WBC count of 17400 cells $/ \mu \mathrm{L}$ with polymorph nuclear (PMN) differential cell count of $61 \%$, erythrocyte sedimentation rate (ESR) $1=77 \mathrm{~mm} / \mathrm{h}$, and one plus C-reactive protein (CRP).

renal parenchymal involvement $(\mathrm{P}>0.05$ for all). ESR1 $\geq 30 \mathrm{~mm} / \mathrm{h}$, presence of bacteriuria on U/A and positive CRP had the highest sensitivities for predicting renal defect on TC-99 DMSA scan (100\%, 83\% and 75\% respectively), while the lowest sensitivities were for proteinuria in U/A and urine $S G \leq 1010$ (57\% and 58\% respectively. Normal renal US had a very low sensitivity for predicting absence of renal parenchymal defects on renal scan (23\%). The highest specificity and positive predictive value (PPV) were due to urine SG $\leq 1010$ (75\% and $85.7 \%$, respectively), and ESR1 $\geq$ $30 \mathrm{~mm} / \mathrm{h}$ had the highest negative predictive value (NPV) for predicting true APN.

In a study conducted by Choi et al. (22), they divided children with febrile UTI into three groups: the group with abnormal urinalysis (U/A) and positive U/C, those with negative $U / A$ and positive $U / C$, and cases with negative $U / C$ and positive U/A findings. They found a lower serum level of CRP in children with only positive U/C compared with the other two groups. WBC count was not different among the three groups. A lower urine SG was found in patients with only positive U/C. In our series, means \pm SD urine SG, WBC count and differential count of PMN were not signif- 


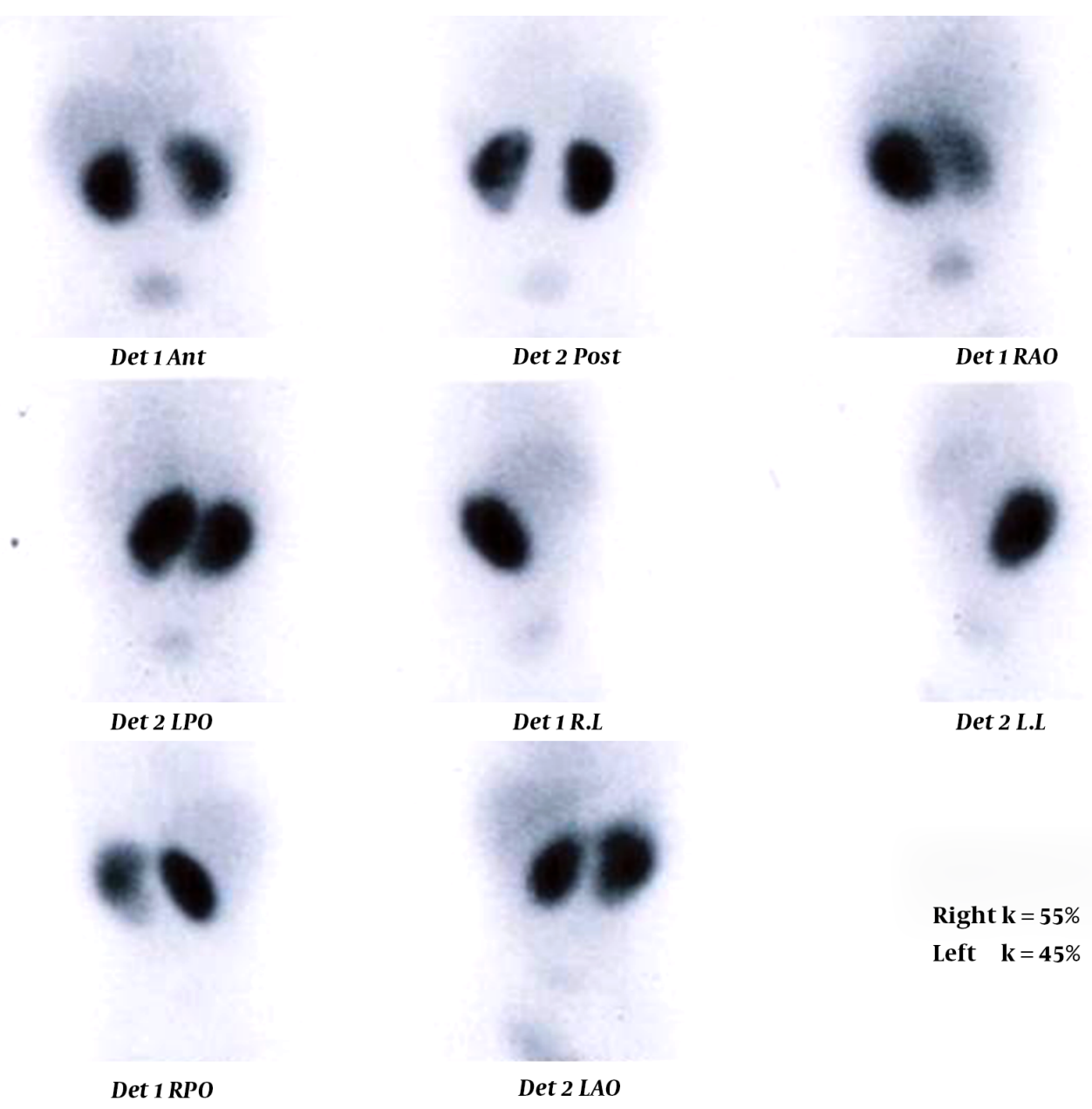

Figure 4. TC 99-DMSA scan of an 8-month-old girl. Left kidney has normal size with mildly decreased tracer uptake through the kidney. The patient's body temperature was $39^{\circ} \mathrm{C}$. Urine examination showed specific gravity of 1005 , trace protein, bacteriuria, negative nitrite test, and mild to moderate pyuria. Kidney ultrasonography showed mild hydronephrosis in the right kidney. CBC revealed WBC count of 22100 cells/ $\mu \mathrm{L}$ with polymorphnuclear (PMN) differential cell count of $72 \%$, erythrocyte sedimentation rate (ESR) and C-reactive protein (CRP) were not checked.

icantly different between cases with positive versus those with negative $\mathrm{U} / \mathrm{C}(\mathrm{P}>0.05$ for all). Whereas, serum ESR was significantly higher in those with positive compared to negative cultures $(\mathrm{P}=0.035)$. Uptake defects on TC 99DMSA scan were reported in four cases of $\mathrm{U} / \mathrm{C}$ negative and eleven $\mathrm{U} / \mathrm{C}$ positive cases.

It has been suggested that CRP levels are not predictive of APN in patients with febrile UTI (32), whereas axillary temperature $\geq 39^{\circ} \mathrm{C}$, leukocyte count $\geq 13500 \mathrm{~mm}^{3}$ are good indicators of renal involvement. Similar to this study, positive CRP was not a good indicator for true APN in our patients either. In contrast to their cases, in our study, body temperatures $\geq 39^{\circ} \mathrm{C}$ had a low sensitivity (64\%) and specificity (50\%) for renal involvement in APN. The sensitivity, specificity, and NPV of WBC count $\geq 15,000$ cells $/ \mu \mathrm{L}$ for predicting renal involvement were low. This marker was frequently considered as a serologic marker for differentiation of bacterial from viral infections in febrile cases.

Sensitivities of U/A, ESR and CRP are low for predicting acute pyelonephritis (33). Nammalwar et al. (34) studied 42 and 26 cases of culture positive and negative APN, respectively. In their study, $92.9 \%$ of cases with culture positive UTI had parenchymal uptake defect/defects in DMSA. In our cases, 11 out of 15 (74\%) culture positive patients showed defect/defects on renal scan. In contrast to our findings, an extended study by Mohkam et al. (23) revealed significant differences in WBC and urine leukocyte count, ESR and age between patients with normal and abnormal 99mTc-DMSA scan results ( $\mathrm{P}=0.03,0.003,0.008$ and 0 04, respectively).

Ataei et al. (35) assessed cases with first documented 
Table 3. Sensitivity, Specificity, Negative and Positive Predictive Values Variables for Predicting Renal Parenchyma Involvement in Renal Scan ${ }^{\mathrm{a}}$

\begin{tabular}{|c|c|c|c|c|}
\hline Variable & Sensitivity ${ }^{\mathbf{b}}$ & Specificity $^{\mathrm{c}}$ & PPV $^{d}$ & NPV $^{e}$ \\
\hline Urine $S G \leq \mathbf{1 0 1 0}^{\mathrm{f}}$ & 58 & 75 & 85.7 & 37.5 \\
\hline Positive CRP ${ }^{\mathrm{f}}$ & 75 & 50 & 75 & 50 \\
\hline$E S R, \geq 30 \mathrm{~mm} / \mathbf{h}^{\mathrm{f}}$ & 100 & 25 & 78 & 100 \\
\hline Leukocyte count, $\geq 15,000$, cells $/ \mu \mathbf{L}^{\mathrm{f}}$ & 61 & 50 & 80 & 28.5 \\
\hline Body temperature $\geq 39,{ }^{\circ} \mathrm{C}^{\mathrm{f}}$ & 64 & 50 & 81.8 & 28.5 \\
\hline Normal renal US & 23 & 66 & 66.6 & 23 \\
\hline Proteinuria in $U / A^{f}$ & 57 & 25 & 57 & 11 \\
\hline Severe pyuria (many WBC on urine sediment) ${ }^{f}$ & 61 & 40 & 72.7 & 28.5 \\
\hline Bacteriuria on $U / A^{f}$ & 83 & 20 & 71 & 33 \\
\hline
\end{tabular}

${ }^{\mathrm{a}}$ Values are expressed as \%.

${ }^{\mathrm{b}}$ Sensitivity was measured by number of true positives/number of true positives + number of false negatives.

${ }^{\mathrm{c}}$ Specificity was measured by number of true negatives/number of true negatives + number of false positives.

${ }^{\mathrm{d}}$ Negative predictive value (NPV) was measured by number of true negatives/number of negative calls.

${ }^{\mathrm{e}}$ Positive predictive value (PPV) was measured by number of true positives/number of positive calls.

${ }^{\mathrm{f}}$ All predictive values were assessed for presence of renal parenchymal involvement in renal scan.

${ }^{\mathrm{g}}$ All predictive values were assessed for absence of renal parenchymal involvement in renal scan.

febrile UTI. Of 52 cases, 41 (78.8\%) had abnormal cortical scintigraphy at the time of admission (seven unilateral and 34 bilateral). In our study, which included children younger than 5 years (14 cases; 70\%) and those older and equal to 5 years (six cases; 30\%), of 15 cases with renal parenchymal defect/defects on renal scan, two cases (14\%) were older than 5 years old and the remainder were younger or equal to 5 years old $(\mathrm{P}=0.718)$. In addition, we found that renal cortical involvement in APN is as common in infants $(\leq 2$ years $)$ as older children $(P=0.292)$. Seven of eight (88\%) infants and eight of the 12 patients who were older than 2 years old (67\%) had cortical uptake defect/defects on TC 99 DMSA scan.

It has been estimated that cortical scintigraphy shows defects two times as much as US and four times as much as IVP (36). We found US findings consistent with renal parenchymal involvement in 3 cases including increased renal size (one case), and increased cortical echogenicity (2 subjects). All of these patients had abnormal findings on TC 99 DMSA scan. It means that only three out of 15 (20\%) patients with uptake defects on renal scintigraphy were recognizable by US.

Jung et al. (1) found that using CRP levels, urine protein/creatinine ratio, urine sodium levels, and urine sodium/potassium ratio had a sensitivity, specificity, positive and negative predictive values (PPV and NPV) $84 \%$, $70 \%, 59 \%$, and $89 \%$, respectively for predicting true APN. In our study using positive CRP as a predictive factor for renal parenchymal involvement in APN, sensitivity, specificity, PPV and NPV were 75\%, 50\%, 75\% and 50\%, respectively. In our evaluation, urinary excretion of sodium \pm potas- sium, which are indicators of tubular function, were not used as predictive factors for renal involvement. Instead of these two indexes of tubular function, we evaluated roles of changes of urine SG as a predictive factor for renal involvement in APN. The sensitivity, specificity, PPV and NPV of urine $\mathrm{SG} \leq 1010$ for prediction of true APN were $58 \%, 75 \%$, $85.7 \%$ and $37.5 \%$, respectively.

Study in experimental models (rats) had demonstrated concentration defects in pyelonephritis that could be rapidly reversed (15). Association between chronic UTIs and impaired renal concentrating ability is well known. Reduced urinary maximum concentration ability is the earliest evidence of invasion of renal medulla by bacterial microorganism (16). Reduced concentrating capacity during APN has been confirmed by different studies. Damage of distal and collecting tubules that return to normal within 4 to 6 weeks after treatment of the infection are responsible for urine concentration defects (17).

We assessed random non-fasting urinary SG in a group of children with APN on presentation. In our cases, although random urinary specific gravities were lower in cases with renal involvement compared to those without, the difference was not significant (Table 2). The concentrating defect could not account for any detectable defect in salt or water transport in cortical nephrons. This disturbance is probably due to changes in urea and water permeability of the collecting ducts (30).

Summary: ESR $1 \geq 30 \mathrm{~mm} / \mathrm{h}$ is a sensitive marker with high NPV for predicting renal involvement in febrile UTI. Traditional urine inflammatory markers including dipstick and urinary sediment parameters (severity of pyuria, 
urine SG and proteinuria) are not sensitive and specific indexes for predicting renal involvement in children with febrile UTI. This was true for non-specific traditional serologic markers such as CRP and WBC count and differential cell count.

Limitations of our study: Among index tests used in the current study, only kidney US was a test that undoubtedly is operator dependent. The other index tests were reported as standard methods that did not seem operator dependent. Lack of measuring inter-raters and intra-rater reliability for kidney US was a main limitation of our study, but for other index tests and also reference standard, measuring reliability was not necessary. Our study included low sample size and negative results such as low sensitivity and specificity of tests may be affected by this factor. Therefore, conducting a study with similar design and sufficient patients' number will be more informative, but the positive results are valuable including high sensitivity of ESR $\geq 30$ $\mathrm{mm} / \mathrm{h}$.

\section{Acknowledgments}

We appreciate Dr. Ataran, Hebrani, Esmaeeli, Ghaneh and Azarfar for their assistance, and also research and development section of Mashhad university of Medical Sciences for sponsoring the budgets of research.

\section{Footnotes}

Authors' Contributions: The study was designed by Mitra Naseri. The collection of study data and evaluation of results were done by Mitra Naseri and Malihe Banihasan. The remaining tasks for preparing the manuscript were done by Mitra Naseri.

Funding/Support: The study was funded by a research grant from research and development section of Mashhad university of Medical Sciences. The registration number is 930544. Name of registry is predictive values of renal ultrasonography and TC99-DMSA scan in predicting vesicoureteral reflux in children with febrile UTI.

\section{References}

1. Jung SJ, Lee JH. Prediction of Cortical Defect Using C-Reactive Protein and Urine Sodium to Potassium Ratio in Infants with Febrile Urinary Tract Infection. Yonsei Med J. 2016;57(1):103-10. doi: 10.3349/ymj.2016.57.1.103. [PubMed: 26632389].

2. Busch R, Huland $\mathrm{H}$. Correlation of symptoms and results of direct bacterial localization in patients with urinary tract infections. J Urol. 1984;132(2):282-5. [PubMed: 6737578].

3. Printza N, Farmaki E, Piretzi K, Arsos G, Kollios K, Papachristou F. Acute phase 99mTc-dimercaptosuccinic acid scan in infants with first episode of febrile urinary tract infection. World J Pediatr. 2012;8(1):526. doi: 10.1007/s12519-012-0335-7. [PubMed: 22282382].
4. Majd M, Rushton HG. Renal cortical scintigraphy in the diagnosis of acute pyelonephritis. Semin Nucl Med. 1992;22(2):98-111. [PubMed: 1317065].

5. Handmaker H. Nuclear renal imaging in acute pyelonephritis. Semin Nucl Med. 1982;12(3):246-53. [PubMed: 6289455].

6. Traisman ES, Conway JJ, Traisman HS, Yogev R, Firlit C, Shkolnik A, et al. The localization of urinary tract infection with $99 \mathrm{mTc}$ glucoheptonate scintigraphy. Pediatr Radiol. 1986;16(5):403-6. [PubMed: 3462650].

7. Sty JR, Wells RG, Starshak RJ, Schroeder BA. Imaging in acute renal infection in children. AJR Am J Roentgenol. 1987;148(3):471-7. doi: 10.2214/ajr.148.3.471. [PubMed: 3544745].

8. Bjorgvinsson E, Majd M, Eggli KD. Diagnosis of acute pyelonephritis in children: comparison of sonography and 99mTc-DMSA scintigraphy. AJR Am J Roentgenol. 1991;157(3):539-43. doi: 10.2214/ajr.157.3.1651644. [PubMed: 1651644].

9. Winberg J, Bollgren I, Kallenius G, Mollby R, Svenson SB. Clinical pyelonephritis and focal renal scarring. A selected review of pathogenesis, prevention, and prognosis. Pediatr Clin North Am. 1982;29(4):801-14. [PubMed: 6125926].

10. Ransley PG, Risdon RA. Reflux nephropathy: effects of antimicrobial therapy on the evolution of the early pyelonephritic scar. Kidney Int. 1981;20(6):733-42. [PubMed: 7038262].

11. Glauser MP, Lyons JM, Braude AI. Prevention of chronic experimental pyelonephritis by suppression of acute suppuration.J Clin Invest. 1978;61(2):403-7. doi: 10.1172/JCl108951. [PubMed: 621280].

12. Ayazi P, Mahyar A, Daneshi MM, Jahani Hashemi H, Pirouzi M, Esmailzadehha N. Diagnostic Accuracy of the Quantitative C-Reactive Protein, Erythrocyte Sedimentation Rate and White Blood Cell Count in Urinary Tract Infections among Infants and Children. Malays J Med Sci. 2013;20(5):40-6. [PubMed: 24643248].

13. Gurgoze MK, Akarsu S, Yilmaz E, Godekmerdan A, Akca Z, Ciftci I, et al. Proinflammatory cytokines and procalcitonin in children with acute pyelonephritis. Pediatr Nephrol. 2005;20(10):1445-8. doi: 10.1007/s00467-005-1941-6. [PubMed:16079986].

14. Naseri M. Alterations of peripheral leukocyte count, erythrocyte sedimentation rate, and C-reactive protein in febrile urinary tract infection. Iran J Kidney Dis. 2008;2(3):137-42. [PubMed: 19377227].

15. Kaye D, Rocha H. Urinary concentrating ability in early experimental pyelonephritis. J Clin Invest. 1970;49(7):1427-37. doi:10.1172/JCI106360. [PubMed: 4914680].

16. Martinez-Maldonado M, Opava-Stitzer S. In: Pathophysiology of the Kidney. Kurtzman NA, Martinez-Maldonado M, editors. Michigan, Mich: Thomas Publisher; 1977. pp. 992-1028.Pathophysiology of clinical disorders of urine concentration and dilution.

17. Berg U. Renal function in acute febrile urinary tract infection in children: pathophysiologic aspects on the reduced concentrating capacity. Kidney Int. 1981;20(6):753-8. [PubMed: 7334747].

18. Kass EJ, Fink-Bennett D, Cacciarelli AA, Balon H, Pavlock S. The sensitivity of renal scintigraphy and sonography in detecting nonobstructive acute pyelonephritis. JUrol. 1992;148(2 Pt 2):606-8. [PubMed: 1640534].

19. Pediatric Task Group of the EANM . A radiopharmaceuticals schedule for imaging pediatrics. Eur J Nucl Med. 1990;2:98-111.

20. Bossuyt PM, Reitsma JB, Bruns DE, Gatsonis CA, Glasziou PP, Irwig L, et al. STARD 2015: an updated list of essential items for reporting diagnostic accuracy studies. BMJ. 2015;351:h5527. doi: 10.1136/bmj.h5527. [PubMed: 26511519].

21. Nicavar A, Sharifian M, Mohkam M. Assessment of fever,WBC,ESR and CRP in first urinary tract infection.J Qazvin Univ Med sci. 2004;31:41-4.

22. Choi DM, Heo TH, Yim HE, Yoo KH. Evaluation of new American Academy of Pediatrics guideline for febrile urinary tract infection. Korean J Pediatr. 2015;58(9):341-6. doi: 10.3345/kjp.2015.58.9.341. [PubMed: 26512260]. 
23. Mohkam M, Maham S, Rahmani A, Naghi I, Otokesh B, Raiiati H, et al. Technetium Tc 99m dimercaptosuccinic acid renal scintigraphy in children with acute pyelonephritis: correlation with other imaging tests. Iran J Kidney Dis. 2010;4(4):297-301. [PubMed: 20852370].

24. Hoberman A, Charron M, Hickey RW, Baskin M, Kearney DH, Wald ER. Imaging studies after a first febrile urinary tract infection in young children. N Engl J Med. 2003;348(3):195-202. doi: 10.1056/NEJMoa021698. [PubMed: 12529459].

25. Riccabona M, Avni FE, Blickman JG, Dacher JN, Darge K, Lobo $\mathrm{ML}$, et al. Imaging recommendations in paediatric uroradiology: minutes of the ESPR workgroup session on urinary tract infection, fetal hydronephrosis, urinary tract ultrasonography and voiding cystourethrography, Barcelona, Spain, June 2007. Pediatr Radiol. 2008;38(2):138-45. doi: 10.1007/s00247-007-0695-7. [PubMed: 18071685].

26. Lim R. Vesicoureteral reflux and urinary tract infection: evolving practices and current controversies in pediatric imaging. AJR Am J Roentgenol. 2009;192(5):1197-208. doi: 10.2214/AJR.08.2187. [PubMed: 19380542].

27. Jack SE. In: Nelson textbook of pediatrics. Kliegman R. M., Stanton B. St. , Geme JW, Schor NF, Behrman RE, editors. Philadelphia: Elsevier Saunders; 2011. pp. 1829-34.Urinary tract infections.

28. Pecile P, Miorin E, Romanello C, Falleti E, Valent F, Giacomuzzi F, et al. Procalcitonin: a marker of severity of acute pyelonephritis among children. Pediatrics. 2004;114(2):e249-54. [PubMed: 15286264].

29. Jung JI, Lim DH, Yim HE, Park MS, Yoo KH, Hong YS, et al. Fever Duration and Renal Scar in Pediatric Urinary Tract Infection. J Korean Soc Pediatr Nephrol. 2008;12(1):70. doi:10.3339/jkspn.2008.12.1.70.

30. Levtchenko EN, Lahy C, Levy J, Ham HR, Piepsz A. Role of Tc-99m DMSA scintigraphy in the diagnosis of culture negative pyelonephritis. Pediatr Nephrol. 2001;16(6):503-6. [PubMed:11420916].

31. Majd M, Rushton HG, Jantausch B, Wiedermann BL. Relationship among vesicoureteral reflux, P-fimbriated Escherichia coli, and acute pyelonephritis in children with febrile urinary tract infection.J Pediatr. 1991;119(4):578-85. [PubMed:1681043].

32. Ansari Gilani K, Modaresi Esfeh J, Gholamrezanezhad A, Gholami A Mamishi S, Eftekhari M, et al. Predictors of abnormal renal cortical scintigraphy in children with first urinary tract infection: the importance of time factor. Int Urol Nephrol. 2010;42(4):1041-7. doi 10.1007/s11255-009-9650-x. [PubMed: 19798584].

33. Biggi A, Dardanelli L, Pomero G, Cussino P, Noello C, Sernia O, et al. Acute renal cortical scintigraphy in children with a first urinary tract infection. Pediatr Nephrol. 2001;16(9):733-8. doi: 10.1007/s0046710160733. [PubMed: 11511988].

34. Nammalwar BR, Vijayakumar M, Sankar J, Ramnath B, Prahlad N. Evaluation of the use of DMSA in culture positive UTI and culture negative acute pyelonephritis. Indian Pediatr. 2005;42(7):691-6. [PubMed: 16085971].

35. Ataei N, Madani A, Habibi R, Khorasani M. Evaluation of acute pyelonephritis with DMSA scans in children presenting after the age of 5 years. Pediatr Nephrol. 2005;20(10):1439-44. doi: 10.1007/s00467005-1925-6. [PubMed: 16082551].

36. Mandell GA, Eggli DF, Gilday DL, Heyman S, Leonard JC, Miller JH. In: Society of nuclear medicine procedure guidelines manual. Washington, Wash: Society of nuclear medicine; 2003. pp. 195-8.Society of nuclear medicine procedure guideline for renal cortical scintigraphy in children. 